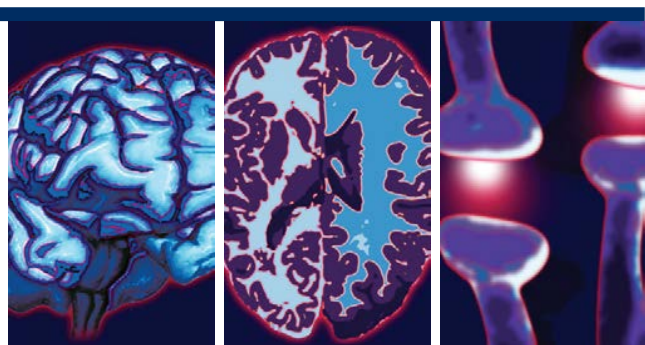

\title{
Analgesic and Anti-Inflammatory Effects of Oxycodone with Adjuvant Drugs in an Experimental Study of Nociceptive and Neuropathic Pain
}

\author{
Wojciech Leppert ${ }^{1,+}$, Michal Szulc², Michal Kaczmarek², Martyna Rochowiak², Ewa Kaminska², Przemyslaw L. \\ Mikolajczak2,3
}

\begin{abstract}
Objective: Opioids are often combined with adjuvants to treat symptoms that accompany pain and with adjuvant analgesics to treat neuropathic pain. Herein, we aim to investigate the analgesic and anti-inflammatory effects of oxycodone and selected adjuvants in rats.

Methods: Analgesic and anti-inflammatory effects of oxycodone were assessed after single subcutaneous (SC) (0.56 $\mathrm{mg} / \mathrm{kg})$ injections in rats, with the following drugs: midazolam $(0.3 \mathrm{mg} / \mathrm{kg})$, haloperidol $(0.45 \mathrm{mg} / \mathrm{kg}), \mathrm{ketamine}(0.3$ $\mathrm{mg} / \mathrm{kg}$ ), hyoscine butylbromide $(1.7 \mathrm{mg} / \mathrm{kg})$, levomepromazine $(0.35 \mathrm{mg} / \mathrm{kg})$, and metoclopramide $(1.0 \mathrm{mg} / \mathrm{kg})$. Analgesia was assessed by the tail flick test. Anti-inflammatory activity was evaluated using a plethysmometer after carrageenan-induced edema. For neuropathic pain, analgesia was explored using the tail flick and von Frey tests. Neuropathic pain was induced by vincristine $(0.1 \mathrm{mg} / \mathrm{kg}$, i.p.) in male Wistar rats.
\end{abstract}

Results: All tested combinations of oxycodone with particular adjuvants showed increased analgesia in comparison to oxycodone alone. Compared to oxycodone alone, combinations with midazolam, haloperidol, hyoscine butylbromide, and levomepromazine prolonged analgesia. Anti-inflammatory activities were observed after coadministration of oxycodone paired with haloperidol and ketamine, which is a new aspect of the pharmacological profile of oxycodone. In the neuropathic pain model, vincristine lowered pain threshold in rats and inhibited growth of normal rat body weight. Oxycodone in combination with adjuvant analgesics showed more potent analgesia than oxycodone alone, especially in the tail-flick test. In most cases, the maximum effects were observed for 15-30 min since combined SC administration.

Conclusions: Analgesic and anti-inflammatory effects were observed in oxycodone combined with selected adjuvants in rats; although the mechanism of these interactions is not yet well understood. Further studies should test these combinations after chronic administration and assess the benefits and risks associated with the use of the tested combinations in humans.

\section{Keywords}

Adjuvants, Adverse effects, Analgesia, Drugs, Oxycodone, Pain, Rats.

\section{Introduction}

The European Association for Palliative Care (EAPC) recommends morphine along with oxycodone and hydromorphone as first-line oral opioids for the management of moderateto-severe pain in cancer patients [1]. Although morphine is also recommended by the European Society for Medical Oncology (ESMO) as the first-line opioid, it is oxycodone that also functions as the first-line opioid with similar efficacy and adverse events (AE) profile [2]. Oxycodone analgesia is predominantly associated with agonist effects on $\mu-$ and, probably also, $\kappa$-opioid receptors [3]. While the oral route of oxycodone administration is preferred in cancer patients, subcutaneous (SC) or intravenous (IV) routes are preferred when the pain cannot be effectively treated by the oral administration.

Cancer patients suffer not only from pain but also from other concurrent distressing symptoms, 
such as nausea/vomiting, swallowing difficulties, dyspnea, and delirium. These patients require opioid administration for effective pain relief along with concurrent use of adjuvant drugs that provide effective relief of the aforementioned symptoms. In this case, opioid analgesics are most often administered subcutaneously in a singlesyringe mixture with one or more adjuvants (antiemetics and anxiolytics) administered via a butterfly needle. This simple method of drug administration requires no painful injections and may be easily established and managed, especially in stay-at-home patients [4].

Oxycodone is co-administered with antiemetics such as metoclopramide and hyoscine butylbromide, haloperidol, and levomepromazine in patients suffering from nausea and vomiting [5]. Haloperidol and levomepromazine may be used for the control of psychiatric symptoms such as delirium [6]. Patients suffering from severe dyspnea often benefit from co-administration of the short-acting benzodiazepine - midazolam - with morphine [7] or oxycodone [8]. However, there exists only limited knowledge of pharmacodynamic oxycodone interactions with the aforementioned, commonly used adjuvant drugs.

The International Association for the Study of Pain (IASP) defines neuropathic pain (NP) as pain initiated or caused by a primary lesion or dysfunction in the nervous system; thus, NP may be caused by any disease or injury to the nervous system. It is estimated that $7-8 \%$ of the general population in Europe suffer from NP, but $30-40 \%$ of patients with diabetes have symptoms suggestive of neuropathy [9]. Moreover, different types of pain occur in as many as $90 \%$ of patients during cancer, and it is predicted that at least $15-20 \%$ of patients may suffer from NP during the course of the disease [10]. This is significant because opioids and nonsteroidal anti-inflammatory drugs are among the most commonly used medication in clinical practice, and their use can subsequently induce unexpected drug interactions and/or produce several adverse reactions. However, literature regarding the pharmacodynamic interaction of oxycodone with the aforementioned, commonly used adjuvant analgesics in the treatment of NP is rather scarce [11].

Therefore the aims of this study was to investigate the analgesic and anti-inflammatory effects of oxycodone co-administered with selected adjuvant drugs, namely: midazolam, haloperidol, ketamine, hyoscine butylbromide, levomepromazine, and metoclopramide in rats, and further study the effect of the same drugs in a rat model of vincristine-induced NP.

\section{Animals and Methods}

\section{- Reagents and compounds}

The following drugs and substances were used: Oxycodone [OXY] (OxyNorm $10 \mathrm{mg} /$ $\mathrm{mL}$, solution for injections/concentration for preparation of solution for infusions, Norpharma A/S, Denmark); midazolam [MID] (Midanium $1 \mathrm{mg} / \mathrm{mL}$, solution for injections, Warsaw Pharmaceutical Factory, Polfa, Poland); haloperidol [HAL] (Haloperidol WZF $5 \mathrm{mg} / \mathrm{mL}$, solution for injections, Warsaw Pharmaceutical Factory, Polfa, Poland); ketamine [KET] (Ketanest $50 ; 50 \mathrm{mg} / \mathrm{mL}$, solution for injections, Pfizer Europe, UK); hyoscine butylbromide [HYO] (Buscolysin $20 \mathrm{mg} / \mathrm{mL}$, solution for injections, Sopharma Warsaw, Poland); levomepromazine [LEV] (Tisercin $25 \mathrm{mg} / \mathrm{mL}$, solution for injections, EGIS Pharmaceuticals PLC, Hungary); metoclopramide [MET] (Metoclopramidum $5 \mathrm{mg} / \mathrm{mL}$ Polpharma; solution for injections, Polpharma SA, Poland); carrageenan (Sigma-Aldrich, USA); water for injections (Polpharma SA, Poland); 0.9\% saline solution [saline] (0.9\% Natrium Chloratum inj., Frenius-Kabi, Poland); and vincristine [VIN] (Vincristine Sulfate inj., USP).

Preparation of $1 \%(2 \mathrm{mg} / 0.2 \mathrm{~mL})$ carrageenan suspension: The compound was suspended in water, then warmed to a temperature of approximately $37^{\circ} \mathrm{C}$. Drug solutions were prepared in water for a SC administration such that the counted drug dose was in a volume range of 0.1-0.3 mL: HAL, KET, LEV and MID were diluted to a concentration of $0.5 \mathrm{mg} / \mathrm{mL}$, whereas OXY and HYO to a concentration of 1 and $2 \mathrm{mg} / \mathrm{mL}$, respectively; MET was already available in an appropriate concentration.

\section{- Animals and drug treatment}

The rats were housed in white, plastic cages (50 x 30 x $20 \mathrm{~cm}$ ) with sawdust. The rats were kept in groups of 5-6 animals per group, and each group was placed in separate cages. All the rats (mean weight: $355 \pm 3 \mathrm{~g}$ ) had ad libitum access to water and standard laboratory chow (Labofed B, Factory of Feeding Stuff "Morawski", Kcynia, Polska, ISO 22000) throughout the study period. The cages were placed in rooms with standard air temperature $\left(20 \pm 2^{\circ} \mathrm{C}\right)$, humidity $(65-75 \%)$ 
and a controlled 12-h light and dark cycle. The study was conducted between 8 am and $10 \mathrm{pm}$ at the Department of Pharmacology, Poznan University of Medical Sciences, in accordance with ethical guidelines for investigations of experimental pain in conscious animals [12]. The study protocol was approved by the local ethical committee of the Laboratory Animals Experimentation in Poznan (No. 58/2015 and 16/2016).

\section{Experiment 1}

\section{- Drug treatment}

A total of 8 groups of male Wistar rats were used in this part of study; all drugs were administered subcutaneously (SC) and groups were constructed in the following way:

Control: $0.4 \mathrm{~mL}$ water for injection (SC), (vehicle); OXY: oxycodone at a dose of $0.56 \mathrm{mg} /$ $\mathrm{kg}$ and $0.2 \mathrm{~mL}$ vehicle; $\mathrm{OXY}+\mathrm{MID}$ : $\mathrm{OXY}$ and midazolam $(0.3 \mathrm{mg} / \mathrm{kg})$; OXY + HAL: OXY and haloperidol $(0.45 \mathrm{mg} / \mathrm{kg})$; OXY + KET: OXY and ketamine $(0.3 \mathrm{mg} / \mathrm{kg})$; OXY + HYO: OXY and hyoscine butylbromide $(1.7 \mathrm{mg} / \mathrm{kg})$; OXY + LEV: OXY and levomepromazine $(0.35 \mathrm{mg} /$ $\mathrm{kg})$; OXY + MET: OXY and metoclopramide (1 $\mathrm{mg} / \mathrm{kg})$.

\section{- Pharmacological tests and schemes of experiment 1}

The tail-flick was used to determine analgesic effects [13]. The anti-inflammatory effects were assessed using a plethysmometer.

\section{- Tail flick test: assessment of analgesic effects}

This test explores the time to appearance of a pain reaction induced by a thermal stimulus directed at a rat's tail by a concentrated light beam and voluntary tail withdrawal allows to measure of the excess of pain threshold. The measurements were conducted using Tail-flick Analgesia Meter (Ugo Basile, Italy); directly before drug administration and after 15, 30, 60, and 120 min. The maximal time (cut off) of measuring the animals' reactions was limited to $20 \mathrm{~s}$ because of the risk of tissue damage.

\section{- Carrageenan test: assessment of anti- inflammatory effects}

Skin inflammation was induced in the right hind paws by topical application of $2 \mathrm{mg} / \mathrm{paw}$ of carrageenan dissolved in $0.2 \mathrm{~mL}$ of $0.9 \%$ saline solution [14]. The rear left paw acted as the control and received the same volume of $0.9 \%$ saline solution. The single doses of the compounds (dissolved in water for injection) were administered SC 30 min before carrageenan injection. The rate of edema in both paws was measured before carrageenan injection (baseline) and $1,3,6$, and $10 \mathrm{~h}$ after drug injections by using the plethysmometer (Hugo Sachs Electronic, Germany).

Change in rat paw thickness was evaluated using the following equation:

$\Delta \mathrm{V}=(\mathrm{Lc}-\mathrm{Lw})-(\mathrm{Rc}-\mathrm{Rw})$, where

$\mathrm{V}$ : value expressing change in the paw thickness against baseline (before inflammation)

Lw: left paw thickness before carrageenan injection

Rw: right paw thickness before carrageenan injection

Lc: left paw thickness $1,3,6$ or $10 \mathrm{~h}$ after drug injection

Rc: right paw thickness $1,3,6$ or $10 \mathrm{~h}$ after drug injection.

The assessment of anti-inflammatory effects was performed on the next day after Tail flick test using the same rats used in the same groups as in the Tail flick test (Figure 1).

\section{Experiment 2}

\section{- Drug treatment}

A total of 10 groups of male Wistar rats were used in this part of study. All drugs were given SC, except vincristine which was given intraperitoneally (i.p.) and groups were constructed in the following way: Control: 0.2 $\mathrm{mL}$ (i.p.) and $0.2 \mathrm{~mL}$ (SC) of water for injection (vehicle); OXY alone: oxycodone $(0.56 \mathrm{mg} /$ $\mathrm{kg}$ ) and $0.2 \mathrm{~mL}$ water for injection (i.p.); VIN: vincristine $(0.1 \mathrm{mg} / \mathrm{kg}$, i.p.) dissolved in saline; VIN + OXY: VIN - group initially receiving vincristine at a dose of $0.1 \mathrm{mg} / \mathrm{kg}$ (i.p.) and $\mathrm{OXY}$ and $0.2 \mathrm{~mL}$ water for injection; VIN + OXY + HAL: VIN and OXY and haloperidol $(0.45 \mathrm{mg} /$ $\mathrm{kg})$; VIN + OXY + KET: VIN and OXY and ketamine $(0.3 \mathrm{mg} / \mathrm{kg}) ; \mathrm{VIN}+\mathrm{OXY}+\mathrm{HYO}$ : VIN and OXY and hyoscine butylbromide (1.7 $\mathrm{mg} / \mathrm{kg}) ; \mathrm{VIN}+\mathrm{OXY}+\mathrm{LEV}$ : VIN and OXY and levomepromazine $(0.35 \mathrm{mg} / \mathrm{kg})$; VIN + OXY + MET: VIN and OXY and metoclopramide (1 $\mathrm{mg} / \mathrm{kg}) ; \mathrm{VIN}+\mathrm{OXY}+\mathrm{MID}: \mathrm{VIN}$ and OXY and midazolam $(0.3 \mathrm{mg} / \mathrm{kg})$. 
First day

\begin{tabular}{|c|c|c|c|}
\hline $\begin{array}{l}\text { base } \\
\text { line }\end{array}$ & $\begin{array}{l}\text { vehicle/drug(s) } \\
\text { administration }\end{array}$ & Tail flick measurement (4x) & \\
\hline | & | & | & | \\
\hline-30 & 0 & $15 \quad 30$ & 120 \\
\hline
\end{tabular}

Second day

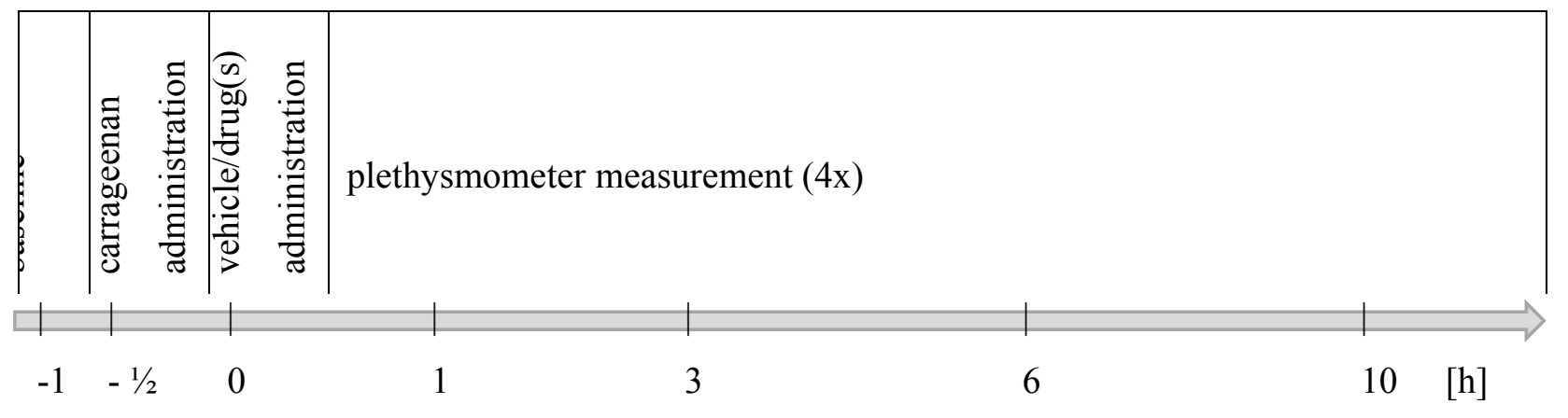

Figure 1: Scheme of assessment of analgesic effects using Tail flick test and anti-inflammatory activities using plethysmometer measurement (Experiment 1).

\section{- Neuropathic pain model}

The NP model was established by administering vincristine (VIN) $(0.1 \mathrm{mg} / \mathrm{kg}$, i.p.) to rats (5 days VIN and next 2 days only saline; the system was repeated twice over 2 consecutive weeks) according to Aley et al. [15]. After NP induction, the rats were administered OXY alone for the next 5 days (without VIN) or OXY in combination with the above mentioned 6 drugs (without VIN) as above mentioned (Drug treatment).

\section{- Tail-flick test}

The tail-flick test was performed as in Experiment 1.

\section{- Von Frey test}

During the von Frey test, the pain threshold was tested with a mechanical stimulus produced by use of von Frey filaments automated system (Ugo Basile, Italy) [16]. A few minutes before the measurement, the rat was placed in a transparent cage, the lower part of which is made of wire mesh. In the middle part of the cage, the soles of the right paw paddle interact with increasing stimulus, and the time of behavioral response is measured, such as the withdrawal of a paw from the applied stimulus. The maximum pressure force was 50 grams, increasing in 10 seconds. Each rat was measured before drug administration (baseline $-\mathrm{t}=0 \mathrm{~min}$ ) and at 15 ,
30, 60, and 120 min after drug administration.

The von Frey test was performed on the next day after Tail flick test using the same rats used in the same groups as in the Tail flick test (Figure 2).

\section{- Statistical analysis}

The results were expressed as arithmetic means \pm SEM. Statistical analysis was carried out using the Statistica 12.5 package. Statistical comparison of results was carried out using ANOVA followed by Fisher's least significant difference post hoc test for detailed data analysis. A p-value of $<0.05$ was considered statistically significant.

\section{Results}

The study's experiments were conducted according to the depiction in the Chapter Animals and Methods. The rats were weighed on the day of the experiment.

\section{Experiment 1}

\section{- Analgesic effects of oxycodone combined with selected adjuvants in the tail-flick test}

For each of the groups, a statistically significant difference was found at least once compared with the control and OXY-alone groups. The results for all groups are shown in Table 1. 
Analgesic and Anti-Inflammatory Effects of Oxycodone with Adjuvant Drugs in an Experimental Study of Nociceptive and Neuropathic Pain

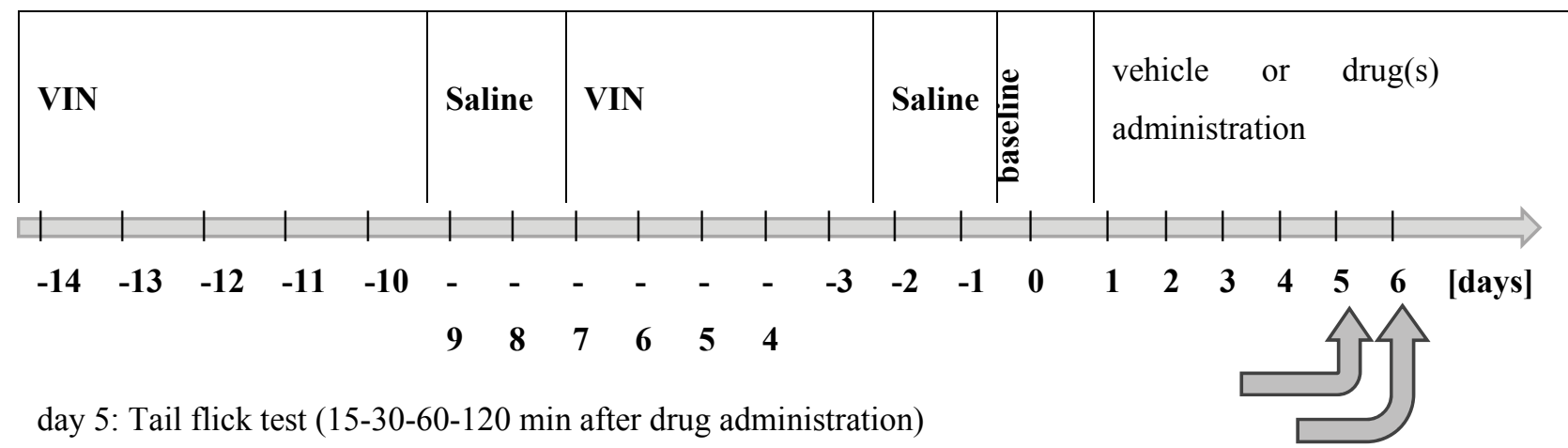

day 6: von Frey test (15-30-60-120 min after drug administration)

Figure 2: Scheme of assessment of analgesic effects using Tail flick test and von Frey test in vincristine-induced (VIN) neuropathic pain model (Experiment 2).

Table 1: Results of the tail flick test for all groups.

\begin{tabular}{|c|c|c|c|c|c|c|}
\hline \multirow{3}{*}{ Group } & \multirow{3}{*}{$\mathbf{N}$} & \multicolumn{5}{|c|}{ Tail-flick response } \\
\hline & & $t_{0}$ & After 15 min & After $30 \mathrm{~min}$ & After $60 \mathrm{~min}$ & After $120 \mathrm{~min}$ \\
\hline & & \multicolumn{5}{|l|}{ Time [s] } \\
\hline Control & 11 & $2.40 \pm 0.17$ & $2.25 \pm 0.20$ & $2.18 \pm 0.20$ & $2.30 \pm 0.17$ & $2.06 \pm 0.24$ \\
\hline OXY & 11 & $2.26 \pm 0.52$ & $4.69 \pm 0.65^{*}$ & $3.66 \pm 0.55^{*}$ & $2.21 \pm 0.35$ & $2.42 \pm 0.20$ \\
\hline OXY+MID & 10 & $3.29 \pm 0.24$ & $12.66 \pm 1.92 * \wedge$ & $14.07 \pm 2.50 * \wedge$ & $5.48 \pm 1.28^{* \wedge}$ & $4.25 \pm 1.24$ \\
\hline $\mathrm{OXY}+\mathrm{HAL}$ & 10 & $2.44 \pm 0.32$ & $13.36 \pm 1.96 * \wedge$ & $8.81 \pm 2.13^{* \wedge}$ & $6.58 \pm 1.99 * \wedge$ & $2.63 \pm 0.44$ \\
\hline $\mathrm{OXY}+\mathrm{KET}$ & 10 & $2.94 \pm 0.26$ & $8.65 \pm 1.85^{* \wedge}$ & $9.64 \pm 2.02^{* \wedge}$ & $3.66 \pm 0.54$ & $3.70 \pm 0.44$ \\
\hline $\mathrm{OXY}+\mathrm{HYO}$ & 10 & $2.08 \pm 0.28$ & $7.68 \pm 2.01 * \wedge$ & $8.10 \pm 1.97^{* \wedge}$ & $5.62 \pm 0.95^{* \wedge}$ & $4.85 \pm 1.32 * \wedge$ \\
\hline OXY+LEV & 10 & $2.62 \pm 0.42$ & $11.68 \pm 2.00 * \wedge$ & $11.63 \pm 1.97^{* \wedge}$ & $7.13 \pm 1.24^{*} \wedge$ & $4.65 \pm 0.90^{*}$ \\
\hline $\mathrm{OXY}+\mathrm{MET}$ & 10 & $2.20 \pm 0.39$ & $11.35 \pm 1.84^{* \wedge}$ & $8.83 \pm 2.08^{*} \wedge$ & $4.28 \pm 1.23$ & $3.89 \pm 0.53$ \\
\hline \multicolumn{7}{|c|}{ Means \pm SEM } \\
\hline \multicolumn{7}{|c|}{$\mathrm{N}:$ number of rats } \\
\hline \multicolumn{7}{|c|}{ *: significant differences vs. Control group, $p<0.05$} \\
\hline \multicolumn{7}{|c|}{ ^: significant differences vs. oxycodone-alone group, $p<0.05$} \\
\hline
\end{tabular}

Administration of OXY alone and with adjuvant drugs showed a statistically significant analgesic activity in the tail-flick test performed on rats [ANOVA main effect $F(7,74)=5.07$, p $<0.00001]$ and indicated a significant effect of time on this type of activity [ANOVA, $\mathrm{F}(4,296)=73.8 ; \mathrm{p}<0.00001]$. The interaction between group and time effect also showed high significance [ANOVA II: $\mathrm{F}(28,296)=4.21 ; \mathrm{p}<$ $0.00001]$.

The effect of OXY in the tail-flick test showed statistically significant differences after 15 and 30 min ( $p<0.001)$, as compared with the control group (Table 1), which confirmed the analgesic effects of OXY. OXY with MID in the tail-flick test showed statistically significant differences after 15 and $30 \mathrm{~min}(\mathrm{p}<0.001)$ as well as after $60 \mathrm{~min}(\mathrm{p}<0.05)$, compared with the control group. Further, this combination also showed statistically significant changes after 15 and 30 $\min (\mathrm{p}<0.001)$ as well as after $60 \min (\mathrm{p}<0.05)$ post administration as compared with OXY alone (Table 1). Enhanced and prolonged analgesic effects were induced by MID with OXY. OXY combined with HAL in the tail-flick test showed statistically significant differences after 15 and 30 $\min (\mathrm{p}<0.001)$ as well as after $60 \min (\mathrm{p}<0.05)$, as compared with the control group. Similarly, this combination showed statistically significant changes after 15 and 30 minutes $(\mathrm{p}<0.001)$ and after 60 minutes $(\mathrm{p}<0.05)$ post administration, compared with OXY alone (Table 1).

Enhanced and prolonged analgesic effects were induced by HAL with OXY. OXY with KET in this test induced statistically significant differences after 15 and $30 \mathrm{~min}(\mathrm{p}<0.001)$, as compared with the control group. Compared with OXY alone, this combination induced statistically significant changes after 15 and 30 $\min (\mathrm{p}<0.001)$ post administration (Table 1$)$. Enhanced analgesic effects were shown by KET with OXY. OXY with HYO in the tail-flick 
test showed statistically significant differences after 15 and $30 \mathrm{~min}(\mathrm{p}<0.001)$ as well as after 60 and $120 \mathrm{~min}(\mathrm{p}<0.05)$, as compared with the control group. Compared with OXY alone, this combination showed statistically significant changes after 15 and $30 \mathrm{~min}(p$ $<0.001)$ as well as after 60 and $120 \mathrm{~min}(\mathrm{p}<$ 0.05 ) post administration (Table 1 ). Improved and prolonged analgesic effects were induced by HYO with OXY. OXY with LEV also resulted in statistically significant differences after 15, 30, and $60 \mathrm{~min}(\mathrm{p}<0.001)$ as well as after $120 \mathrm{~min}$ ( $\mathrm{p}<0.05)$, as compared with the control group. Compared with OXY alone, this combination resulted in statistically significant changes after 15, 30, and $60 \mathrm{~min}(\mathrm{p}<0.001)$ (Table 1). Enhanced and prolonged analgesic effects were induced by LEV with OXY. OXY with MET in this test induced statistically significant differences after 15 and $30 \mathrm{~min}(\mathrm{p}<0.001)$, as compared with the control group. Compared with OXY alone, this combination induced statistically significant changes after 15 and 30 min $(\mathrm{p}<0.001)$ after administration (Table 1). Enhanced analgesic effects were induced by MET with OXY.

\section{- Results of anti-inflammatory effects of oxycodone with selected adjuvants}

Administration of OXY alone and with adjuvant drugs showed a statistically significant antiinflammatory effect in carrageenan-induced edema on rats [ANOVA main effect $F(7,73)=$ 3.34, $\mathrm{p}=0.0039$ ] and indicated a significant effect of time on this type of activity [ANOVA, $\mathrm{F}(4,292)=209.7 ; \mathrm{p}<0.00001]$. The interactions between group and time effect also showed a high significance [ANOVA II: F $(28,292)=1.97$; $\mathrm{p}=0.0031]$ (Table 2).
OXY did not induce any statistically significant changes in inflammation, as compared to the control group (Table 2). This result suggests a lack of anti-inflammatory effect of OXY. In an experiment conducted in the control group, normal induction of the inflammatory state was confirmed. The anti-inflammatory effects of OXY with HAL displayed statistically significant differences after 1,3 , and $6 \mathrm{~h}(\mathrm{p}<0.05)$, as compared to the control group. Compared to OXY administered alone, this combination displayed significant differences after 1 and $3 \mathrm{~h}$ $(\mathrm{p}<0.05)$ (Table 2), which proved the antiinflammatory effect of the combination of HAL with OXY.

The anti-inflammatory effects of OXY with KET displayed statistically significant differences after $3 \mathrm{~h}(\mathrm{p}<0.05), 6 \mathrm{~h}(\mathrm{p}<0.001)$, and $10 \mathrm{~h}$ ( $\mathrm{p}<0.05$ ), as compared to the control group. Compared to OXY administered alone, this combination displayed significant differences after $3 \mathrm{~h}(\mathrm{p}<0.05), 6 \mathrm{~h}$, and $10 \mathrm{~h}(\mathrm{p}<0.001)$ of its administration (Table 2 ), which proved the anti-inflammatory effect of the combination of KET with OXY. In this experiment, statistically significant differences were observed in the case of HAL and KET (at least two significant effects, as compared to the control and OXY-alone groups) and in the case of HYO and MET. An addition of other compounds (LEV and MID) to OXY did not show any significant antiinflammatory effects.

\section{- Experiment 2}

Administration of OXY alone and with adjuvant drugs in the by VIN-induced NP model showed significant analgesic activity in the tail-flick test performed on rats [ANOVA, main effect:

\section{Table 2: Results of anti-inflammatory effects in all groups.}

\begin{tabular}{|c|c|c|c|c|c|c|}
\hline \multirow{2}{*}{ Group } & \multirow{2}{*}{$\mathbf{N}$} & \multicolumn{5}{|l|}{$\Delta V[m L]$} \\
\hline & & $\mathbf{t}_{0}$ & After $1 \mathrm{~h}$ & After $3 \mathrm{~h}$ & After $6 \mathrm{~h}$ & After $10 \mathrm{~h}$ \\
\hline Control & 11 & $0.01 \pm 0.02$ & $0.18 \pm 0.06$ & $0.53 \pm 0.08$ & $0.57 \pm 0.07$ & $0.42 \pm 0.06$ \\
\hline OXY & 11 & $0.11 \pm 0.03$ & $0.26 \pm 0.03$ & $0.52 \pm 0.04$ & $0.51 \pm 0.04$ & $0.47 \pm 0.05$ \\
\hline OXY+MID & 10 & $-0.02 \pm 0.06$ & $0.20 \pm 0.03$ & $0.56 \pm 0.07$ & $0.52 \pm 0.06$ & $0.37 \pm 0.07$ \\
\hline $\mathrm{OXY}+\mathrm{HAL}$ & 10 & $-0.05 \pm 0.04 \wedge$ & $0.00 \pm 0.03^{* \wedge}$ & $0.28 \pm 0.05^{* \wedge}$ & $0.40 \pm 0.07^{*}$ & $0.33 \pm 0.05$ \\
\hline OXY+KET & 10 & $0.01 \pm 0.03$ & $0.08 \pm 0.03 \wedge$ & $0.34 \pm 0.03^{* \wedge}$ & $0.27 \pm 0.04 * \wedge$ & $0.20 \pm 0.02 * \wedge$ \\
\hline $\mathrm{OXY}+\mathrm{HYO}$ & 10 & $0.01 \pm 0.03$ & $0.11 \pm 0.03^{\wedge}$ & $0.53 \pm 0.06$ & $0.58 \pm 0.04$ & $0.45 \pm 0.05$ \\
\hline OXY+LEV & 10 & $0.03 \pm 0.02$ & $0.19 \pm 0.06$ & $0.52 \pm 0.10$ & $0.62 \pm 0.10$ & $0.49 \pm 0.10$ \\
\hline OXY+MET & 10 & $0.03 \pm 0.04$ & $0.10 \pm 0.05^{\wedge}$ & $0.41 \pm 0.07$ & $0.46 \pm 0.10$ & $0.47 \pm 0.06$ \\
\hline \multicolumn{7}{|c|}{ Means \pm SEM, N: number of rats } \\
\hline \multicolumn{7}{|c|}{$\begin{array}{l}\Delta \mathrm{V} \text { : difference in the volume of right and left hind paw after inducing inflammation using (for detailed equation, please see Materials and Method } \\
\text { Chapter) }\end{array}$} \\
\hline \multicolumn{7}{|c|}{ *: significant differences vs. control group $(p<0.05)$} \\
\hline \multicolumn{7}{|c|}{$\wedge$ : significant differences vs. oxycodone group $(p<0.05)$} \\
\hline
\end{tabular}


$\mathrm{F}(9,74)=5.07, \mathrm{p}<0.00001]$ and a significant effect on time [ANOVA, time effect: $\mathrm{F}(4,316)$ $=116,5 ; \mathrm{p}<0.00001]$. The interaction between group and time effect also showed high significance [ANOVA, interaction: $\mathrm{F}(36,316)=$ 6.67; $\mathrm{p}<0.00001]$.

Administration of OXY alone in the tail-flick test showed statistically significant differences after 15 and $30 \mathrm{~min}(\mathrm{p}<0.05)$, as compared with the control group (Table 3). VIN-induced NP produced significant lowering of the pain threshold in this test at all time points $(\mathrm{p}<$ 0.05 ) when compared with control values. OXY combined with HAL for NP in the tail-flick test showed statistically significant differences after 15 and $30 \mathrm{~min}(\mathrm{p}<0.05)$, as compared with the control group. Compared with the VIN + OXY group, this combination also showed significant changes after 15 and $30 \mathrm{~min}(\mathrm{p}<0.05)$; the same effect was observed when compared with VIN ( $p$ $<0.05$ ). Similar results were obtained for OXY combined with KET, LEV, MET, and HYO. With respect to the combination of VIN + OXY + MID, stronger analgesic effect were seen only for the 15-min timepoint.

Administration of OXY alone and with adjuvant drugs in vincristine-induced NP showed a statistically significant analgesic activity in the von Frey's test performed on rats [ANOVA, main effect: $F(9,75)=4.79, p=0.00005]$. Additionally, time was a significant factor in this experiment [ANOVA, time effect: $\mathrm{F}(4,300)=$ $71,0, \mathrm{p}<0.00001]$. Moreover, the combination of these two factors (main effect and time) also showed significant differences [ANOVA, interaction: $\mathrm{F}(36,300)=3.01, \mathrm{p}<0.00001]$.
Administration of OXY alone in the von Frey's test showed significant differences after 15 and $30 \mathrm{~min}(\mathrm{p}<0.05)$, as compared with the control group (Table 4). VIN-induced NP produced significant lowering of the pain threshold in this test in the 15-120 min time points ( $\mathrm{p}<$ 0.05 ) when compared with control values. OXY combined with HAL or MET during NP in the von Frey's test showed statistically significant differences after $15 \mathrm{~min}(\mathrm{p}<0.05)$, as compared with the control group. With respect to the combination of VIN + OXY, significant changes were seen only after 15 $\min (\mathrm{p}<0.05)$. Other combinations were not significantly different.

\section{Discussion}

In this study, the analgesic effects of OXY and selected adjuvants (MID, HAL, KET, HYO, LEV and MET) were explored. In the first experiment, the tail-flick test was used and carageenan inflammation was induced to test the antinociceptive and anti-inflammatory effects of oxycodone and the aforementioned selected adjuvants. Taken together, two methods were used in this study to explore the analgesic and anti-inflammatory effects of OXY and selected adjuvants. The dose of OXY used in this study $(0.56 \mathrm{mg} / \mathrm{kg}$ b.w. $)$ was taken from the Kanbara et al. study, wherein after OXY administration (SC), this dose was effective in the treatment of NP in rats [17]. The choice of adjuvants and their doses were based on our earlier studies, in which concurrent analgesic effects of selected adjuvants with tramadol [18] and morphine [19] were explored.

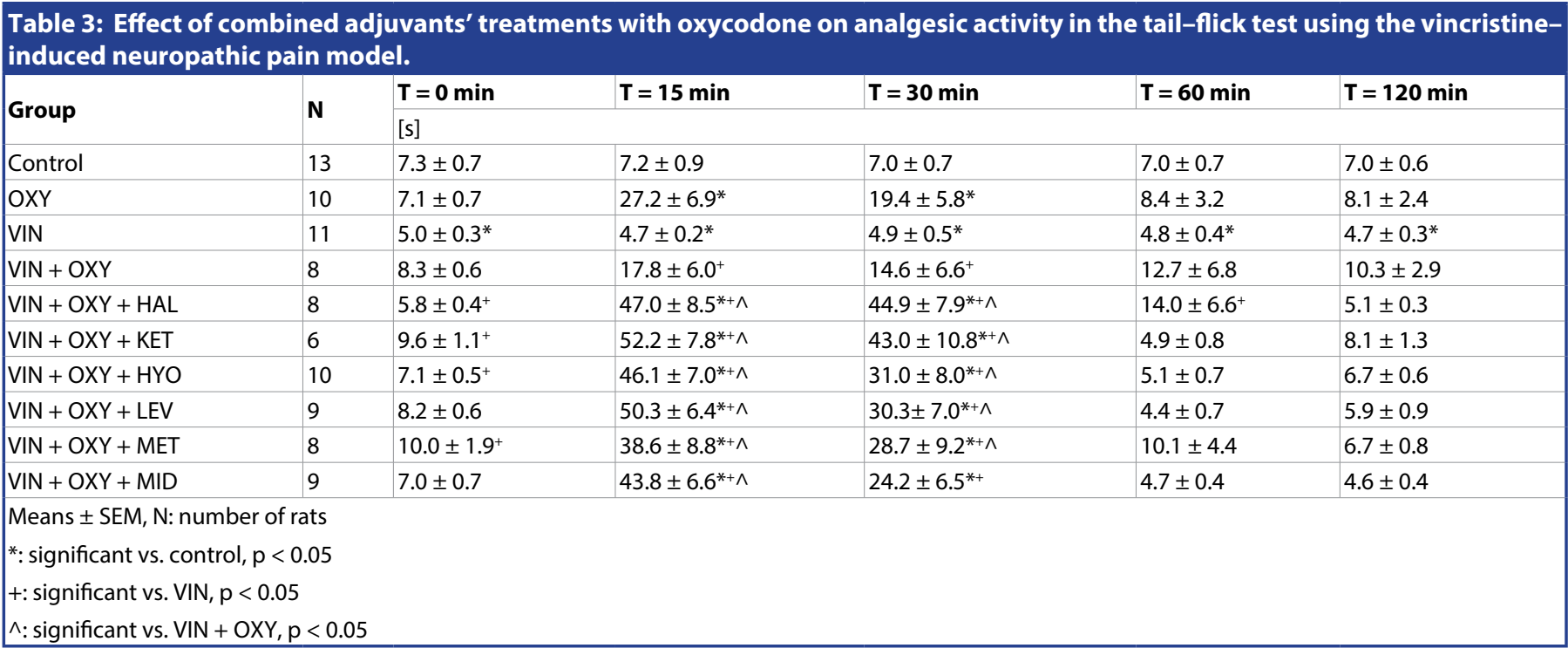




\begin{tabular}{|c|c|c|c|c|c|c|}
\hline \multirow{2}{*}{ Group } & \multirow{2}{*}{$\mathbf{N}$} & $\mathbf{T}=\mathbf{0} \min$ & $T=15 \mathrm{~min}$ & $T=30 \mathrm{~min}$ & $T=60 \mathrm{~min}$ & $T=120 \mathrm{~min}$ \\
\hline & & \multicolumn{5}{|l|}{ [s] } \\
\hline Control & 13 & $30.8 \pm 1.2$ & $29.7 \pm 1.7$ & $28.7 \pm 1.5$ & $29.3 \pm 0.9$ & $28.8 \pm 1.2$ \\
\hline OXY & 10 & $29.6 \pm 1.4$ & $37.1 \pm 1.8^{*}$ & $31.2 \pm 1.2^{*}$ & $27.1 \pm 1.1$ & $25.7 \pm 1.2$ \\
\hline VIN & 14 & $29.2 \pm 1.9$ & $27.5 \pm 1.6^{*}$ & $25.6 \pm 1.3^{*}$ & $24.3 \pm 1.0^{*}$ & $24.0 \pm 0.8^{*}$ \\
\hline $\mathrm{VIN}+\mathrm{OXY}$ & 8 & $27.0 \pm 3.2$ & $31.4 \pm 1.4$ & $28.3 \pm 1.1$ & $23.6 \pm 1.1$ & $22.0 \pm 0.9$ \\
\hline $\mathrm{VIN}+\mathrm{OXY}+\mathrm{HAL}$ & 8 & $24.7 \pm 0.6$ & $38.3 \pm 3.2^{\wedge}$ & $30.6 \pm 1.0$ & $25.3 \pm 1.4$ & $23.6 \pm 1.7$ \\
\hline $\mathrm{VIN}+\mathrm{OXY}+\mathrm{KET}$ & 6 & $24.4 \pm 1.0$ & $33.1 \pm 1.9$ & $26.3 \pm 0.8$ & $22.0 \pm 0.9$ & $20.2 \pm 1.5$ \\
\hline $\mathrm{VIN}+\mathrm{OXY}+\mathrm{HYO}$ & 10 & $23.6 \pm 1.4 \wedge$ & $33.8 \pm 0.8$ & $27.5 \pm 1.3$ & $21.7 \pm 1.5$ & $21.0 \pm 1.2$ \\
\hline VIN + OXY + LEV & 9 & $21.9 \pm 1.5^{\wedge}$ & $35.8 \pm 2.0$ & $29.2 \pm 1.8$ & $23.9 \pm 1.3$ & $21.8 \pm 0.9$ \\
\hline $\mathrm{VIN}+\mathrm{OXY}+\mathrm{MET}$ & 8 & $27.8 \pm 2.1$ & $37.4 \pm 1.9^{\wedge}$ & $31.8 \pm 2.3$ & $26.6 \pm 2.1$ & $24.4 \pm 1.1$ \\
\hline VIN + OXY + MID & 9 & $23.4 \pm 1.6^{\wedge}$ & $31.2 \pm 1.4$ & $28.9 \pm 1.0$ & $25.7 \pm 1.2$ & $23.6 \pm 1.0$ \\
\hline \multicolumn{7}{|l|}{ Means \pm SEM } \\
\hline \multicolumn{7}{|l|}{$\mathrm{N}$ : number of rats } \\
\hline \multicolumn{7}{|c|}{ *: significant vs. control, $p<0.05$} \\
\hline \multicolumn{7}{|c|}{ +: significant vs. VIN, $p<0.05$} \\
\hline \multicolumn{7}{|c|}{$\wedge$ : significant vs. VIN + OXY, $p<0.05$} \\
\hline
\end{tabular}

These selected adjuvants represent different drug groups and consequently possess different mechanisms and effects of pharmacodynamic action. This enabled us to explore several possible mechanisms of synergistic interactions of oxycodone in one study. The tail-flick test is designed to explore analgesic effects on the spinal and supraspinal levels [20]. In this study, OXY alone showed analgesic effects. All adjuvants in combinations with OXY demonstrated synergistic effects when compared to analgesic effects of oxycodone alone. This confirmed the results of other studies that suggested the analgesic effects of MID [21], HAL [22-24], KET [25], HYO [26], LEV [27], and MET [28].

All adjuvants used in this study showed synergism with OXY regarding analgesia, compared to OXY administered alone in the tail-flick test in rats. Combinations of OXY with MID, HAL, $\mathrm{HYO}$, and LEV prolonged the analgesia period when compared to OXY administered alone in the tail-flick test in rats. Combinations of OXY with HAL or KET showed anti-inflammatory effects in the carrageenan model of inflammation in rats.

There is limited knowledge on the possible analgesic effects of the tested drugs. HAL exerts analgesia owing to its antagonistic effect on sigma receptors [22,23] and blockade of NMDA receptors [24]. HYO is effective in clinical practice in patients with visceral colic pain, present especially in patients suffering from bowel obstruction. A combination of opioids and spasmolytics is recommended to provide effective relief from severe colic pain and to reduce the frequency and volume of vomiting [26]. Benefits of concurrent OXY and HYO administration in rats confirm clinical observations in patients with bowel obstruction and colic pain. However, the pharmacodynamic interaction between anticholinergics and opioids remains unclear $[29,30]$. It may be speculated that enhancement of OXY analgesia observed after co-administration with HYO, which acts only peripherally, might be associated with the pharmacokinetic interaction.

MID displays antinociceptive effects when administered intrathecally through the action on GABA-A receptors [31], although it may also have inhibitory effects on opioid analgesia at the supraspinal level by inhibition of the pain inhibitory system. MID may also evoke hyperalgesia and its analgesic effects may be influenced by rats' races [32]. MET is suggested to potentiate opioid analgesia [33] through the interaction with opioid receptors [34] and other putative mechanisms [35], although experimental [36] and clinical data did not confirm these observations [37]. However, it should be noted that conflicting results on opioid and MET analgesic interaction might be due to different dosing schedules and rats races used in the aforementioned experimental studies. LEV administered alone in mice exerts analgesic activity and enhances opioid analgesia [38]. Analgesic efficacy of LEV was also seen in studies conducted in humans [27,39]. It should also be noted that LEV in rats [40] and humans [41] and MET in humans [42] significantly inhibit CYP2D6 activity, which may increase 
OXY levels in plasma and enhance its analgesic effects.

Apart from the analgesic effects, some of the explored compounds such as neuroleptics (HAL and LEV) and benzodiazepine (MID) might have also induced additional sedative and anesthetic effects, in addition to analgesic ones, as part of their pharmacodynamics. In the test exploring the anti-inflammatory effect, carrageenan was used for inducing inflammation, and each rat received $2000 \mu \mathrm{g}$ of carrageenan as a $0.2 \mathrm{~mL}$ solution at a concentration of $1 \%$. This dose was determined based on our previous studies $[14,43]$. Anti-inflammatory effects were not found after administration of OXY alone or after majority of OXY's combinations with adjuvants. However, OXY combinations with HAL or KET displayed significant anti-inflammatory effects. These observations may be justified by the observed anti-inflammatory effects of HAL [44] and KET administered alone [45] or by unveiling such effects in combinations of adjuvant with OXY that was not observed in the case of OXY administered alone.

VIN lowers the pain threshold in rats, which confirms its use as a model substance to induce NP [46-48]. This drug is used during chemotherapy regimens in cancer patients. The administration of OXY in combination with adjuvant drugs (HAL, KET, HYO, LEV, MET, MID) in a NP model exhibits a stronger analgesic effect than OXY alone, that was demonstrated in the tailflick test. However, this was demonstrated to a limited extent in the Von Frey test as OXY and a combination of OXY with KET did not enhance analgesic effects, compared to VIN and OXY alone. As NP mostly refers to central nervous system changes, this discrepancy of the results may be explained by differences between tests used in this part of the study. A tail-flick test demonstrates spinal and supraspinal analgesic effects [15], whereas the von Frey test mainly refers to peripheral effects [16]. The most potent analgesic effect of OXY in combination with the adjuvant drugs occurs 15-30 min after their combined administration, especially in the tailflick test. These effects may be utilized in humans when treating patients suffering from NP.

The current study results might be compared with experimental trials conducted in rats in which morphine or tramadol were concurrently administered with the same adjuvants. Two drugs significantly increased morphine analgesia: HAL and HYO [19]. HAL co-administration also enhanced tramadol analgesia. However, in contrast to the presented study, HYO coadministration did not enhance tramadol analgesia. Contrary to co-administration with morphine, MID enhanced tramadol analgesia and MET and LEV attenuated tramadol antinociception [18]. Results of an experimental study indicate a synergistic interaction of OXY and morphine with pregabalin, combinations that are often used in clinical practice for the treatment of NP in cancer patients [49].

These differences may be evoked by differences in pharmacodynamic interactions of the tested opioids and possible pharmacokinetic interactions with adjuvants as there are significant differences in pharmacodynamics and pharmacokinetic properties of OXY, morphine, and tramadol. OXY displays analgesia through $\mu-$ and probably also $\kappa$-opioid receptors [50] and activation of $\mathrm{GABA}_{B}$ receptors [51]. $\mathrm{OXY}$ is metabolized through the $\mathrm{P}-450$ system, predominantly CYP3A4 to inactive noroxycodone, and to a less extent via CYP2D6 to oxymorphone that displays analgesic effect [52]. Morphine acts exclusively via activation of predominantly $\mu$-opioid receptors and mostly undergoes glucuronidation; it is metabolized through CYP2D6 to a less extent [53]. Tramadol displays the non-opioid component of analgesia; $\mu$-opioid receptors are activated predominantly by an active metabolite (O-desmethyltramadol, M1) that is formed through tramadol Odemethylation catalyzed by CYP2D6 [54].

Several limitations of the study should be addressed. These comprise administration of single doses (or very short term) of the drugs tested, while in patients with chronic pain and other symptoms often repeated or continuous administration is necessary. Another limitation refers to single doses of OXY and tested adjuvants in this study, while an individual dose titration of opioid analgesics and adjuvants is typically recommended in patients with chronic pain and other symptoms. Measurements of the tested compounds in the animals' blood plasma and pharmacokinetic interactions of the study drugs were not explored. In spite of these limitations, to the best of our knowledge for the first time we were able to demonstrate benefits of coadministration of OXY with selected adjuvant drugs used for the treatment of nociceptive (inflammatory) and NP. Further studies should test activities of these combinations in chronic administration and assess benefits and risks associated with their use of in humans. 


\section{Conflict of Interest}

The authors declare no conflict of interests.

\section{Funding}

The study was funded from Poznan University of Medical Sciences.

\section{References}

1. $r$ the European Palliative Care Research Collaborative (EPCRC) on behalf of the European Association for Palliative Care (EAPC): Use of opioid analgesics in the treatment of cancer pain: evidence-based recommendations from the EAPC. Lancet. Oncol 13: e58-e68 2012.

2. Ripamonti $\mathrm{Cl}$, Santini D, Maranzano E, et al. on behalf of the ESMO Guidelines Working Group: Management of cancer pain: ESMO Clinical Practice Guidelines. Ann. Oncol; 23 (Suppl. 7): vii139-vii154 (2012).

3. Kalso E. Oxycodone. J. Pain. Symptom. Manage 29(1), 47-56 (2005).

4. Destro M, Ottolini L, Vicentini L, et al. Physical compatibility of binary and ternary mixtures of morphine and methadone with other drugs for parenteral administration in palliative care. Support Care Cancer 2012; 20: 2501-2509.

5. Glare P, Nikolova T, Tickoo R, et al. An overview of antiemetic medications and the considerations for their use in palliative care. Eur. J. Palliat. Care 19(1), 162-167 (2012).

6. Breitbart W, Alici Y. Evidence-based treatment of delirium in patients with cancer. J. Clin. Oncol 30(1), 1206-1214 (2012).

7. Navigante AH, Castro MA, Cerchietti LC Morphine versus midazolam as upfront therapy to control dyspnea perception in cancer patients while its underlying cause is sought or treated. J. Pain. Symptom. Manage 39(1), 820-830 (2010).

8. Kawabata M, Kaneishi K. Continuous subcutaneous infusion of compound oxycodone for the relief of dyspnea in patients with terminally ill cancer: a retrospective study. Am. J. Hosp. Palliat. Care 30(1), 305-311 (2013).

9. Bouhassira $D$, Lantéri-Minet $M, A$ ttal $N$, et al. Prevalence of chronic pain with neuropathic characteristics in the general population. Pain 136(1), 380-387 (2008).

10. Mulver MR, Boland EG, Bouhassira D, et al. Neuropathic pain in cancer: systematic review, performance of screening tools and analysis of symptom profiles. Br. J. Anaesth 119(1), 765-774 (2017).

11. Nakazawa Y, Okura T, Shimomura K, et al. Drug-drug interaction between oxycodone and adjuvant analgesics in blood-brain barrier transport and antinociceptive effect. J. Pharm. Sci 99(1), 467-474 (2010).
12. Zimmermann M. Ethical guidelines for investigations of experimental pain in conscious animals. Pain; 16(1), 109-110 (1983).

13. D'Amour FE, Smith DL. A method for determining loss of pain sensation. $J$. Pharmacol. Exp. Ther 72(1), 74-79 (1941).

14. Bednarczyk-Cwynar B, Wachowiak N, Szulc M, et al. Strong and long-lasting antinociceptive and anti-inflammatory conjugate of naturally occurring oleanolic acid and aspirin. Frontiers. In. Pharmacology 7(1), 202 (2016).

15. Aley KO, Reichling DB, Levine JD. Vincristine hyperalgesia in the rat: a model of painful vincristine neuropathy in humans. Neuroscience 73(1), 259-265 (1996).

16. Bradman MJ, Ferrini F, Salio C, et al. Practical mechanical threshold estimation in rodents using von Frey hairs/Semmes-Weinstein monofilaments: Towards a rational method. J. Neurosci. Methods 255(1), 92-103 (2015).

17. Kanbara T, Nakamura A, Takasu K, et al. The contribution of Gi/o protein to opioid antinociception in an oxaliplatin-induced neuropathy rat model. J. Pharmacol. Sci 126(1), 264-273 (2014).

18. Okulicz-Kozaryn I, Leppert W, Mikolajczak $P$, et al. Analgesic Effects of Tramadol in Combination with Adjuvant Drugs: An Experimental Study in Rats. Pharmacology 91(1), 7-11 (2013).

19. Leppert W, Okulicz-Kozaryn I, Kaminska $E$, et al. Analgesic effects of morphine in combination with adjuvant drugs in rats. Pharmacology 94(1)m 207-213 (2014).

20. Leandri M, Leandri S, Ghignotti M, et al. The ITFR, impulsive tail flick reflex by short duration nociceptive stimuli. J. Neurosci. Methods 199(1), 69-77 (2011).

21. Ho KM, Ismail H. Use of intrathecal midazolam to improve perioperative analgesia: a meta-analysis. Anaesth. Intensive. Care 36(1), 365-373 (2008).

22. Chien CC, Pasternak GW. Selective antagonism of opioid analgesia by sigma system. J. Pharmacol. Exp Ther 271(1), 1583-1590 (1994).

23. Chien CC, Pasternak GW. Sigma antagonists potentiate opioid analgesia in rats. Neurosci. Lett 190(1), 137-139 (1994).

24. Gallagher MJ, Huang $H$, Lynch DR. Modulation of the N-methyl-D-aspartate receptor by haloperidol: NR2B specific interactions. J. Neurochem 70(1), 2120-2128
(1998).

25. Sarton E, Teppema LJ, Olievier C, et al. The involvement of the mu-opioid receptor in ketamine-induced respiratory depression and antinociception. Anesth. Analg 93(1), 1495-1500 (2001).

26. Ripamonti Cl, Easson AM, Gerdes H. Management of malignant bowel obstruction. Eur. J. Cancer 44(1), 1105-1115 (2008).

27. Petts HV, Pleuvry BJ. Interactions of morphine and methotrimeprazine in mouse and man with respect to analgesia, respiration and sedation. Br. J. Anaesth 55(1), 437-441 (1983).

28. Derry S, Moore RA. Paracetamol (acetaminophen) with or without an antiemetic for acute migraine headaches in adults. Cochrane. Database. Syst. Rev 4 (2013)

29. Li X, Li JX, France CP. Interactions between morphine, scopolamine and nicotine: Schedule-controlled responding in rats. Pharmacol. Biochem. Behav 96(1), 91-95 (2010).

30. Song SW, Kim K, Rhee JE, et al. Butylscopolammonium bromide does not provide additional analgesia when combined with morphine and ketorolac for acute renal colic. Emerg. Med.Australas 24(1), 144-150 (2012).

31. Yanez A, Sabbe MB, Stevens CW, et al. Interaction of midazolam and morphine in the spinal cord of the rat. Neuropharmacology 29(1), 359-364 (1990).

32. Nishiyama T. Analgesic effects of systemic midazolam: comparison with intrathecal administration. Can. J. Anesth 53(1), $1004-$ 1009 (2006).

33. Kamerman PR, Becker N, Fick LG. Interaction between metoclopramide and morphine: enhanced antinociception and motor dysfunction in rats. Clin. Exp. Pharmacol. Physiol 34(1), 106-112 (2007).

34. Boublik JH, Funder JW. Interaction of dopamine receptor ligands with subtypes of the opiate receptor. Eur. J. Pharmacol 15(1), 11-16 (1984).

35. Reddy PM, Shantanu S, Shewade DG, et al Effect of ATP sensitive potassium channel modifiers on antinociceptive effect of metoclopramide. Indian. J. Exp. Biol 39(1), 476-478 (2001).

36. Ung D, Cowan A, Parkman HP, et al. Lack of interaction between metoclopramide and 

of Nociceptive and Neuropathic Pain

morphine in vitro and in mice. Xenobiotica 38(1), 1365-1376 (2008).

37. Driver RP, D'Angelo R, Eisenach JC. Bolus metoclopramide does not enhance morphine analgesia after cesarean section. Anesth. Analg 82(1), 1033-1035 (1996).

38. Beaver WT. A comparison of the analgesic effects of methotrimeprazine and morphine in patients with cancer. Clin. Pharmacol. Ther 7(1), 436-466 (1966).

39. Stiell I, Dufour D, Moher D, et al. Methotrimeprazine vs. meperidine and dimenhydrynate in the treatment of severe migraine: a randomized, controlled trial. Ann. Emerg. Med 20(1), 1201-1205 (1991).

40. Daniel WA, Haduch A, Wojcikowski J. Inhibition of rat liver CYP2D in vitro and after 1-day and long-term exposure to neuroleptics in vivo - possible involvement of different mechanisms. Eur Neuropsychopharmacol 15(1), 103-110 (2005).

41. Vevelstad M, Pettersen S, Tallaksen C, et al. O-demethylation of codeine to morphine inhibited by low-dose levomepromazine. Eur. J. Clin. Pharmacol 65(1), 795-801 (2009).

42. Desta Z, Wu GM, Morocho AM, et al. The gastroprokinetic and antiemetic drug metoclopramide is a substrate and inhibitor of cytochrome P450 2D6. Drug. Metabol. Dis 30(1), 336-343 (2002)

43. Okulicz-Kozaryn I, Zaluska A, Kaminska E, et al. Changes in nociceptive sensitivity induced by carrageenan inflammation evaluated using automated von Frey method. Pol. J. Pharmacol 56(1), 174 (2004).

44. Moots RJ, Al-Saffar Z, Hutchinson D, et al Old drug, new tricks: haloperidol inhibits secretion of proinflammatory cytokines. Ann. Rheum. Dis 58(1), 585-587 (1999).

45. Hirota K, Lambert DG. Ketamine: new uses for an old drug? Br. J. Anaesth 107(1), 123-126 (2011).

46. Higuera ES, Luo ZD. A rat pain model of vincristine-induced neuropathy. Methods. Mol. Med 99(1), 91-98 (2004).

47. Authier N, Gillet JP, Fialip J, et al. A new animal model of vincristine-induced nociceptive peripheral neuropathy. Neurotoxicology 24(1), 797-805 (2003).

48. Cliff J, Jorgensen AL, Lord R, et al. The molecular genetics of chemotherapy-induced peripheral neuropathy: A systematic review and meta-analysis. Crit. Rev. Oncol.Hematol 120(1), 127-140 (2017)

49. Jokinen V, Lilius TO, Laitila J, et al. Pregabalin enhances the antinociceptive effect of oxycodone and morphine in thermal models of nociception in the rat without any pharmacokinetic interactions. Eur. J. Pain 20(1), 297-306 (2016)

50. Riley J, Branford R, Droney J, et al. Morphine or Oxycodone for Cancer-Related Pain? A Randomized, Open-Label, Controlled Trial. J. Pain. Symptom. Manage 49(1), 161-172 (2015).

51. Thibault K, Calvino B, Rivals I, et al. Molecular mechanisms underlying the enhanced analgesic effect of oxycodone compared to morphine in chemotherapy-induced neuropathic pain. PLoS. One 9(1), e91297 (2014).

52. Samer CF, Daali Y, Wagner M, et al. The effects of CYP2D6 and CYP3A activities on the pharmacokinetics of immediate release oxycodone. Br. J. Pharmacol 160(1), 907-918 (2010)

53. Zecca E, Brunelli C, Bracchi $P$, et al. Comparison of the Tolerability Profile of Controlled-Release Oral Morphine and Oxycodone for Cancer Pain Treatment. An Open-Label Randomized Controlled Trial. J. Pain. Symptom. Manage 52(1), 783-794 (2016)

54. Leppert W. Tramadol as an analgesic for mild to moderate cancer pain. Pharmacol. Rep 61(1), 978-992 (2009). 